\title{
Generation of pancreatic $\beta$ cells for treatment of diabetes: advances and challenges
}

\author{
Hussain Md. Shahjalal ${ }^{1,2+}$, Ahmed Abdal Dayem ${ }^{1+}$, Kyung Min Lim ${ }^{1}$, Tak-il Jeon ${ }^{1}$ and Ssang-Goo Cho ${ }^{1 *}$ (D)
}

\begin{abstract}
Human embryonic stem cells (hESC) and induced pluripotent stem cells (hiPSC) are considered attractive sources of pancreatic $\beta$ cells and islet organoids. Recently, several reports presented that hESC/iPSC-derived cells enriched with specific transcription factors can form glucose-responsive insulin-secreting cells in vitro and transplantation of these cells ameliorates hyperglycemia in diabetic mice. However, the glucose-stimulated insulin-secreting capacity of these cells is lower than that of endogenous islets, suggesting the need to improve induction procedures. One of the critical problems facing in vivo maturation of hESC/iPSC-derived cells is their low survival rate after transplantation, although this rate increases when the implanted pancreatic cells are encapsulated to avoid the immune response. Several groups have also reported on the generation of hESC/iPSC-derived islet-like organoids, but development of techniques for complete islet structures with the eventual generation of vascularized constructs remains a major challenge to their application in regenerative therapies. Many issues also need to be addressed before the successful clinical application of hESC/PSC-derived cells or islet organoids. In this review, we summarize advances in the generation of hESC/PSC-derived pancreatic $\beta$ cells or islet organoids and discuss the limitations and challenges for their successful therapeutic application in diabetes.
\end{abstract}

Keywords: Embryonic stem cells (ESC), Induced pluripotent stem cells (iPSC), Differentiation, Pancreatic $\beta$ cell, Islet organoids, Transplantation, $\beta$ Cell maturation

\section{Background}

Diabetes mellitus is a life-threatening disease, and its prevalence is increasing worldwide. The available treatment can neither cure nor completely control the complications of this disorder, which results in substantial losses of life in almost all countries in the world. Furthermore, current life-long treatment strategies impose large social and economic burdens on a family. For the last few decades, human beings have been trying to develop a treatment strategy that can effectively control this disorder and save lives. Despite tremendous efforts, however, humans have been far from success in finding an effective treatment strategy for diabetes.

\footnotetext{
* Correspondence: ssangoo@konkuk.ac.kr; ssangoo33@gmail.com ${ }^{+}$Hussain Md. Shahjalal and Ahmed Abdal Dayem contributed equally to this work.

${ }^{1}$ Department of Stem Cell \& Regenerative Biotechnology and IDASI (Incurable Disease Animal model \& Stem cell Institute), Konkuk University, 120 Neungdong-ro, Gwangjin-gu, Seoul 05029, South Korea Full list of author information is available at the end of the article
}

Type 1 diabetes results from an absolute deficiency of insulin due to $\mathrm{T}$ cell-mediated autoimmune destruction of pancreas $\beta$ cells [1]. The current treatment for type 1 diabetes is solely dependent on the administration of exogenous insulin. Although this approach manages the disease, unwanted risks and long-term complications persist because of the inability to tightly maintain glucose levels within a normal physiological range. Complications include life-threatening episodes of hypoglycemia, as well as long-term complications that include micro- and macro-angiopathy leading to cardiovascular pathologies, kidney failure, and neuropathy. Thus, there is a need for new treatments that provide superior control of blood glucose to minimize these complications [2]. One existing approach to treating diabetes is transplantation of purified human cadaveric islets into the portal vein to replace the destroyed $\beta$ cells of the patients. This procedure typically results in better glycemic control, can render patients insulin independent for prolonged periods of time, and improves overall

(c) The Author(s). 2018 Open Access This article is distributed under the terms of the Creative Commons Attribution 4.0 International License (http://creativecommons.org/licenses/by/4.0/), which permits unrestricted use, distribution, and 
quality of life [3, 4]. Although promising, because of difficulties such as the scarcity of cadaveric donors compared to the large number of diabetic patients, low yield of transplantable islets from cadaveric pancreases, and necessity for chronic immunosuppression to prevent rejection of the allograft $[5,6]$, an alternative source of surrogate cells is needed. Moreover, the number of functional $\beta$ cells that can be extracted from a single cadaveric pancreas is often not enough to restore euglycemia in a single diabetic patient [7]. This also illustrates the need for alternative sources of $\beta$ cells to treat the increasing number of diabetic patients.

Human pluripotent stem cells (hPSCs), including human embryonic stem cells (hESC) and induced pluripotent stem cells (hiPSC), are considered very attractive alternative sources of surrogate $\beta$ cells because of their ability to differentiate into all major somatic cell lineages $[8,9]$. To date, the most success in producing pancreatic $\beta$-like cells from hPSCs has come from approaches that mimic normal pancreas development. Many research groups have followed this approach, which involves exposing the cells to various growth factors and signaling molecules at specific doses and in a particular sequence to successfully differentiate the cells into pancreatic endoderm or endocrine cells (ECs) [2, 10-29]. However, in many studies, a large number of polyhormonal insulin-expressing cells have been observed in culture that resemble transient ECs seen in mid-gestation human fetal pancreases $[10,11,15-17,30-32]$. These polyhormonal cells lack expression of key $\beta$ cell transcription factors and do not secrete insulin in vitro in response to glucose challenge-the hallmark function of bona fide $\beta$ cells [10, 32-34] (Fig. 1a). Concurrently, in several other studies, an alternative strategy has been adopted in which glucose-responsive insulin-secreting cells can be generated following transplantation of $\mathrm{hESC} / \mathrm{iPSC}$-derived pancreatic progenitor cells into ectopic sites in immunodeficient or type 1 diabetic mice [12, 14, 18-21, 26]. In recipient mice, the resulting cells can produce human insulin to reverse diabetes [18, 20, 21] (Fig. 1b). In recent years, optimized differentiation protocols have been successfully developed to generate glucose-responsive insulin-secreting cells in vitro from hESC/iPSC, which express mature $\beta$ cell markers, and transplantation of these

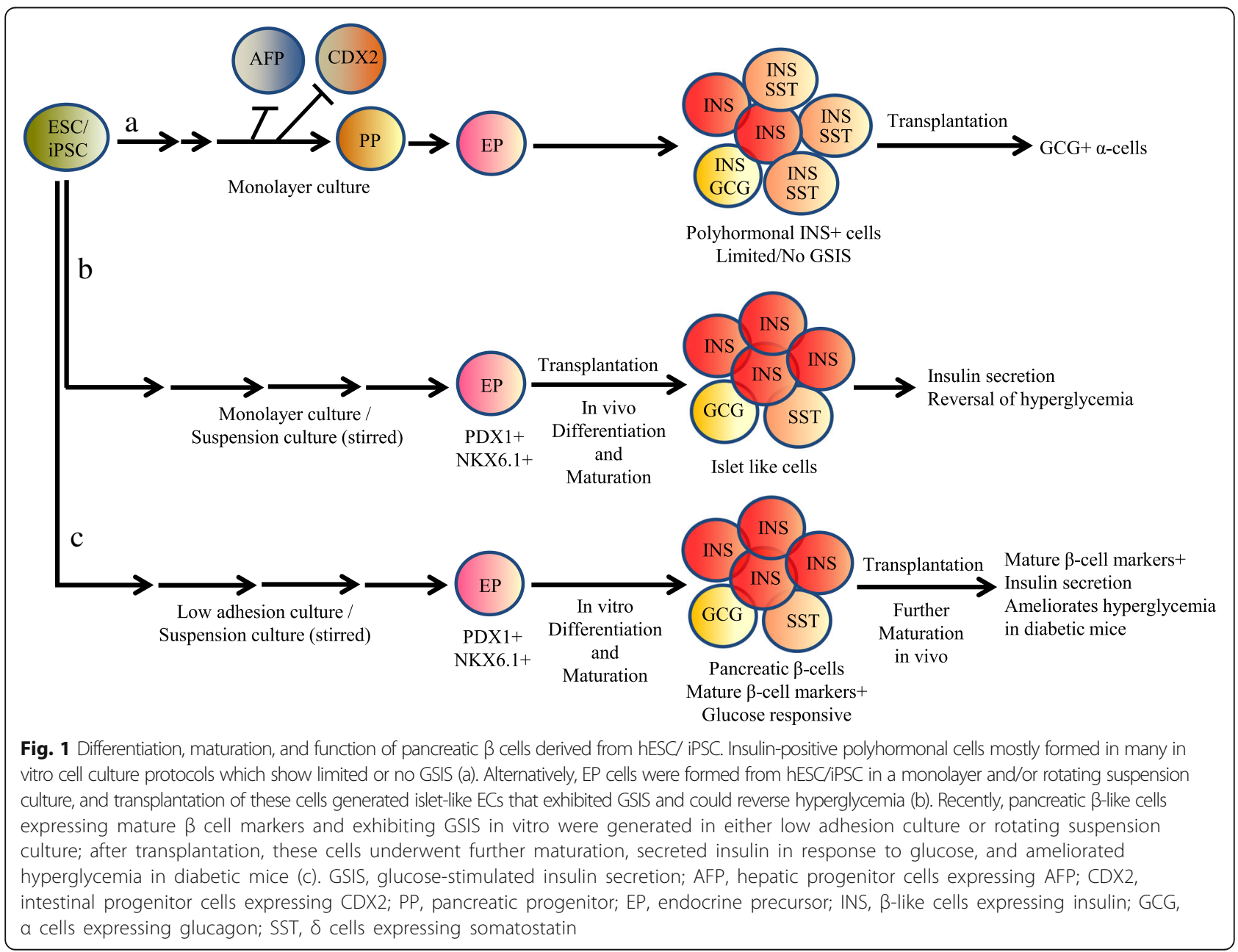


cells has been shown to ameliorate hyperglycemia in diabetic mice $[2,22,23,29]$ (Fig. 1c). The $\beta$-like cells generated show gene expression, ultrastructural characteristics, and glucose responsiveness both in vitro and in vivo, which closely resembling the features of $\beta$ cells found in pancreatic islets $[2,22,23]$. In these multistage protocols, the final cell population has about $30-60 \% \beta$-like cells, and the majority of the remaining cells are relatively uncharacterized cells that can be undifferentiated progenitors or other types of unwanted cells. Thus, improving efficiency, in terms of the percentage of differentiated cells that become $\beta$ cells, remains an important challenge.

Although tremendous success has been achieved in the last few years, low survival rates of hESC/iPSC-derived pancreatic cells after transplantation into ectopic sites in recipients remain a critical problem $[20,25,35]$. Therefore, an efficient culture system that can be used to generate functional and terminally differentiated $\beta$ cells, along with an effective transplantation technique, is needed for clinical application of $\mathrm{hESC} / \mathrm{iPSC}$-derived $\beta$ cells for diabetes treatment. However, phase $1 / 2$ clinical trials for the application of hESC-derived pancreatic progenitors in type 1 diabetes patients have already begun [36]. In this review, we summarize advances in the differentiation of $\mathrm{hESC} / \mathrm{iPSC}$-derived cells into pancreatic $\beta$ cells and islet-like organoids and discuss the limitations and challenges for their successful generation and therapeutic application in type 1 diabetes.

\section{Pluripotent stem cells and their reprogramming}

ESCs show unlimited replicative properties and the potential to differentiate into any adult cell type [37-39]. iPSCs, established from somatic cells of mouse and human [40-42], have the same ability to expand and differentiate as ESCs. Therefore, both ESCs and iPSCs have great potential for use in cell therapies. However, the use of iPSCs has fewer ethical complications than ESCs that are derived from the inner cell mass of living embryos. iPSCs are derived from various somatic cells after exposure to a combination of transcription factors such as Oct3/4, Sox2, Klf4, and c-Myc [40, 41]. iPSC generation is carried out via viral-based and non-viral-based methods as summarized in Fig. 2. These methods are varied in their efficiencies, transduction period, genome

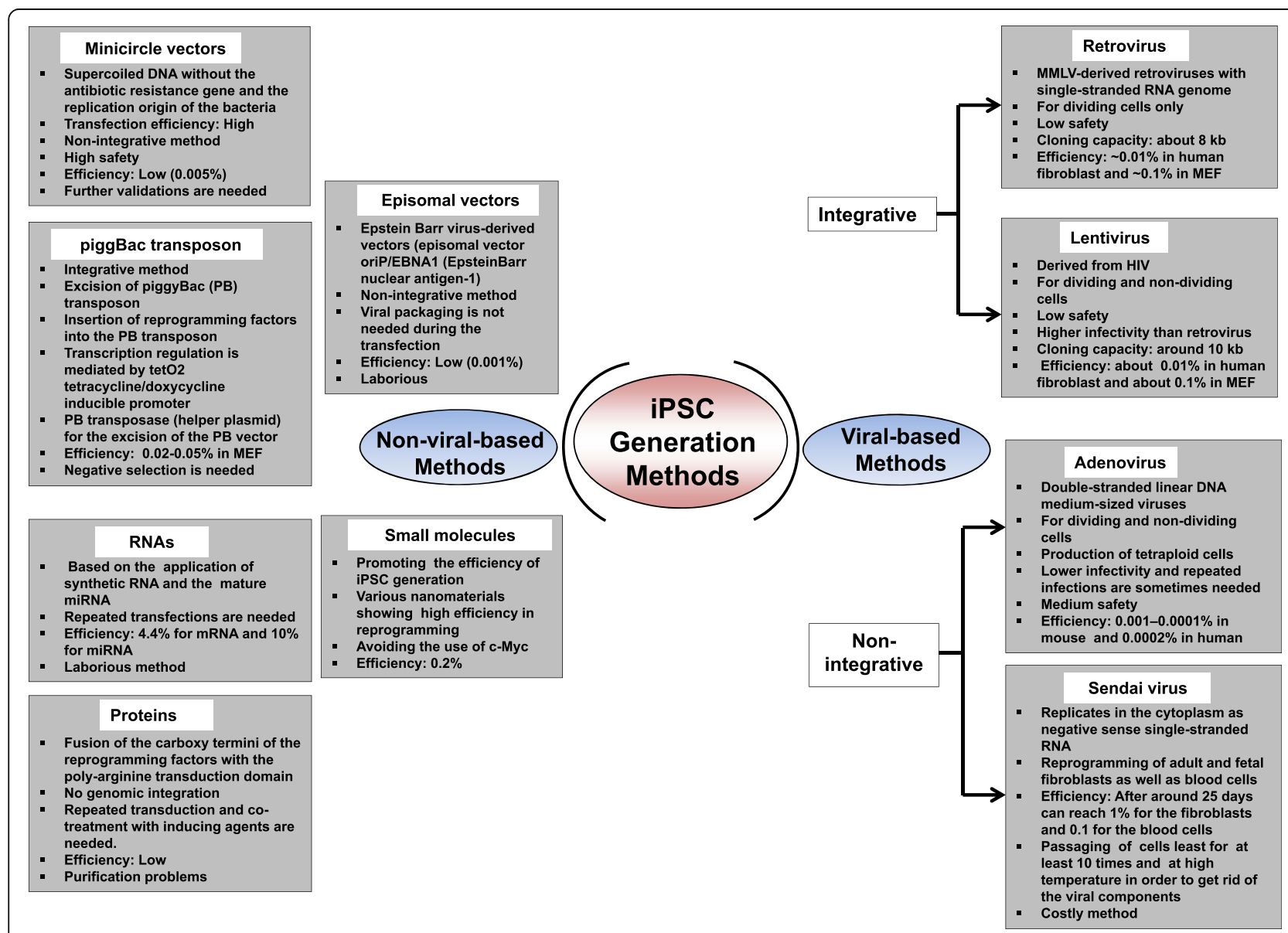

Fig. 2 Generation of iPSCs from various somatic cells. iPSC generation carried out via viral-based and non-viral-based methods are summarized 
integration, and cost [43-48]. Therefore, selection of the reprogramming method determines the further application of the produced iPSC in regenerative medicine. Generally, viral-based methods lead to genome integration and are of low safety, albeit, the high efficiency. Most iPSCs are made using retrovirus vectors, which integrate reprogramming factors into host genomes. Retrovirus vectors can spontaneously infect various cell types and insert their coding genes into host genomes using reverse transcriptase, which allows continuous transgene expression during reprogramming. Retroviral transgene expression continues until the cells become iPSCs, and then, the retroviral promoter is inactivated, possibly because of epigenetic modifications such as histone methylation [49]. This guided reprogramming and automatic silencing mechanism is considered very important for iPSC induction from somatic cells. Recently, several virus-free techniques have been developed for the production of footprint-free iPSCs; their efficient culture techniques have also been established [50-57].

\section{ESCs vs. iPSCs: similarities and differences}

Similar to ESCs, iPSCs have a characteristic morphology, ability to generate embryoid bodies and teratomas, and unlimited proliferation capability in vitro, while they maintain their pluripotency by expressing pluripotency genes. However, several studies have revealed some differences between hESCs and hiPSCs in terms of gene expression profiles [58], epigenetic modifications such as DNA methylation [59], genetic stability [60], imprinted gene expression stability [61], differentiation potentials $[62,63]$, and disease modeling [64]. iPSCs have some "memory" of their somatic origin and therefore are not identical to ESCs. The memory of iPSC may affect their safety [65]. However, there is no sufficient evidence yet to determine whether iPSC memory can be fatal in cell therapies.

\section{Differentiation of hESC/iPSC into pancreatic $\beta$ cells}

Insulin-producing cells with pancreatic $\beta$ cell characteristics were first successfully derived in embryoid bodies from spontaneous differentiation of hESC [66]. Since then, numerous methods to generate pancreatic endoderm or $\beta$-like cells from hESC/iPSC have been reported [2, 10-29]. These studies demonstrated the generation of insulin-positive cells, as well as glucagon- and somatostatin-positive cells (Table 1). However, the percentages of insulin-positive cells obtained in culture vary among the protocols.

The key stages of embryonic pancreas development include development of the definitive endoderm (DE), primitive gut tube (PG), pancreatic progenitor (PP), endocrine progenitor (EP), and hormone-expressing ECs.
Based on information about embryonic pancreas development, each differentiation protocol has been designed to use various cytokines or signaling modulators at specific doses and in particular sequences to activate or inhibit key signaling pathways, including nodal/activin, Wnt, PI3K, fibroblast growth factors (FGF), bone morphogenetic protein (BMP), retinoic acid, hedgehog, protein kinase $\mathrm{C}$, notch, epidermal growth factor, and transforming growth factor- $\beta$ (TGF- $\beta)$. Other growth factors such as insulin-like growth factors 1 and 2, hepatocyte growth factor (HGF), and glucagon-like peptide-1 (GLP-1) or exendin-4 (a peptide analog of GLP-1) have also been used to facilitate differentiation of pancreatic hormone-expressing cells [10, 11, 13, 15, 16, 24]. In addition, various classes of small molecules have been reported to be effective for differentiation of $\mathrm{hESC} / \mathrm{iPSC}$ into insulin-producing cells. Nicotinamide, a poly (ADP-ribose) synthetase inhibitor, is used in some protocols to improve the yield of pancreatic ECs [11, 13, 16, 17, 24]. Further, forskolin (an activator of adenylyl cyclase) and dexamethasone (a synthetic adrenocortical steroid) have been shown to enhance cellular maturation, and these agents can be combined with other small molecules to obtain synergistic effects [17]. Thyroid hormone promotes postnatal $\beta$ cell development and glucose-responsive insulin secretion in rats through the transcription factor MAFA [67]. This insight has increased the use of thyroid hormone in recent protocols to improve glucose responsiveness of hESC/iPSC-derived $\beta$ cells $[22,23,25,27,28,68]$. Several reports have recognized pancreatic progenitors co-expressing Pancreatic and Duodenal Homeobox 1 (PDX1) and NK6 homeobox 1 (NKX6.1) as indispensable precursors of mature pancreatic $\beta$ cells $[18,21,26]$. Differentiation into pancreatic progenitors co-expressing PDX1 and NKX6.1 can be enhanced in vitro by either dissociating densely formed endodermal cells and re-plating these cells at a low density followed by exposure to a longer period of retinoid and FGF10 signaling [68] or cultures with high-density aggregates [26] or rotating a suspension culture after the addition of factors such as ALK5i (a TGF- $\beta$ type I receptor kinase inhibitor II), TBP (a PKC activator), and/or LDN (a BMP inhibitor) [18, 21, 23]. The use of epidermal growth factor (EGF) and nicotinamide in the pancreatic progenitor specification stage can also significantly enhance pancreatic progenitor co-expressing PDX1 and NKX6.1 [69].

\section{Maturation of $\mathrm{hESC} / \mathrm{iPSC}$-derived $\boldsymbol{\beta}$ cells}

The maturation of pancreatic $\beta$-like cells obtained by differentiation from $\mathrm{hESC} / \mathrm{iPSC}$ in vitro remains controversial. In the early studies, either Matrigel or low-density mouse embryonic fibroblast (MEF) was used as a $2 \mathrm{D}$ culture platform on which $\mathrm{hESC} / \mathrm{iPSC}$ were seeded $[10,11,15-17,30-32]$. These protocols 


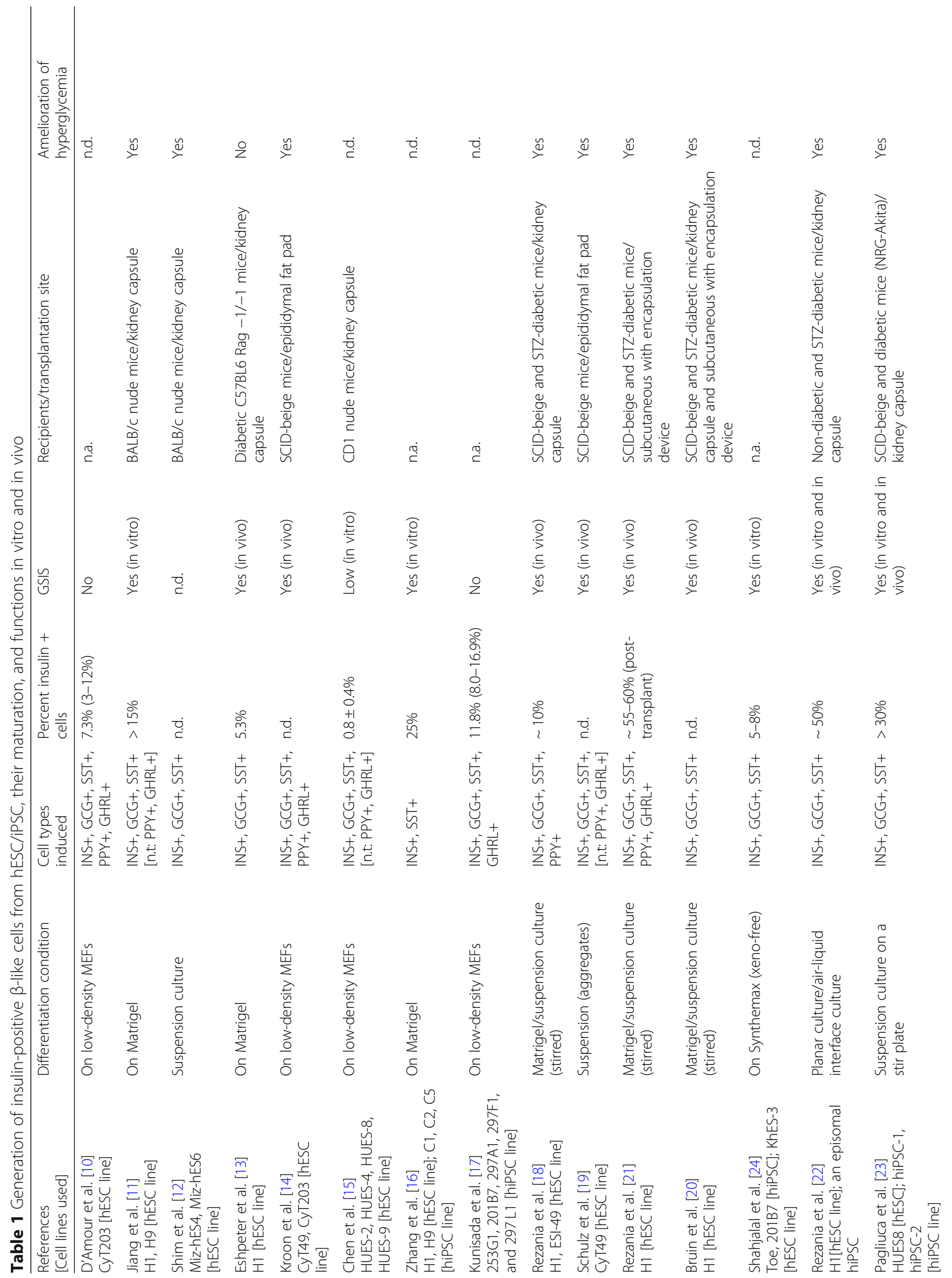




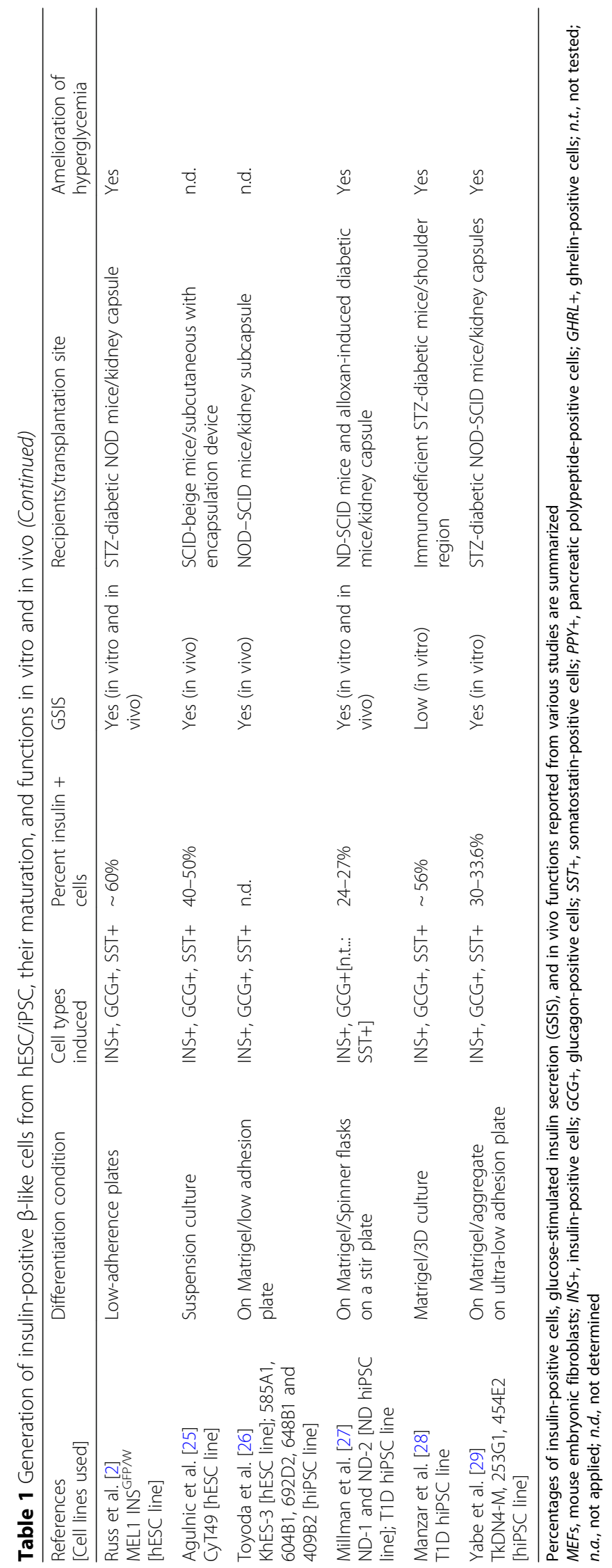


efficiently established PDX1+ progenitors by using retinoic acid in combination with inhibitors of BMP and hedgehog signaling pathways, while simultaneously adding either FGF10 or FGF7. The $\beta$-like cells generated in such monolayer culture were largely polyhormonal insulin-expressing cells (Fig. 1a). Polyhormonal cells lack expression of key $\beta$ cell transcription factors and exhibit limited glucose-stimulated insulin secretion (GSIS) in vitro [10, 32-34]. Formation of non-functional polyhormonal cells is considered the limitation of these protocols. Whether the culture platform or the inappropriate combinations of growth factors in the culture media promote such cells are not clearly known. Varying degrees of in vitro GSIS from hESC/iPSC-derived insulin-positive cells have been reported by several studies, including an approximately 1.7 -fold increase observed by Chen et al. [15], a 2-fold increase noted by Jiang et al. [11] and Zhang et al. [16], and apparently no GSIS reported by D'Amour et al. [10] and Kunisada et al. [17] (Fig. 1a) (Table 1). These differences and low levels of secreted insulin could be due to the generation of varying numbers of polyhormonal cells in culture. The polyhormonal cells may resemble the immature $\beta$ cells observed in mid-gestation human fetal pancreases [70, 71]. The role and fate of polyhormonal cells during human fetal development are poorly understood; however, immunohistochemical characterization indicates that these cells possess an $\alpha$ cell transcription factor profile [72]. Several reports have described the formation of glucagon-expressing $\alpha$ cells in vivo following transplantation of hESC-derived polyhormonal cells [21, 33, 73] (Fig. 1a), and dynamic chromatin remodeling was reported to occur during this transition into matured cell types [73, 74]. Studies of Bruin et al. [32] revealed several key features of polyhormonal insulin-positive cells that differ from those of mature pancreatic $\beta$ cells, including defects in glucose transporter expression, $\mathrm{K}_{\mathrm{ATP}}$ channel function, and prohormone processing enzymes. These deficiencies must be addressed with further protocol modifications to generate hESC/iPSC-derived pancreatic $\beta$ cells that show GSIS in vitro. Although several of these reports described the detection of GSIS in vitro, none of the reported cells were capable of efficiently restoring euglycemia in an in vivo diabetic animal model. To overcome this limitation, an alternative strategy to obtain glucose-responsive insulin-producing cells has been established in several studies [12, 14, 18-21, 26] (Fig. 1b). Most of these studies used Matrigel as the 2D platform for ESC/iPSC monolayer culture, followed by suspension culture with or w/o stirring using low adhesion plate. Continuous stirring promotes cell-cell and cell-matrix interactions within the culture. The resultant EP cells were then transplanted into recipient mice for further differentiation in vivo. These studies demonstrated that $\mathrm{hESC} / \mathrm{iPSC}$-derived pancreatic progenitor cells when transplanted into ectopic sites in immunodeficient or type 1 diabetes mice; they underwent further differentiation and maturation into glucose-responsive insulin-secreting cells, which could reverse diabetes in recipient mice [18, 20, 21] (Fig. 1b) (Table 1), suggesting that pancreatic precursors or immature islet-like cells obtained in vitro could mature in vivo. This also indicates that some in vivo factors are still missing in in vitro growth factor cocktails. Therefore, growth factors and signaling molecules involved in pancreas development need to be better screened to detect their potential abilities to cause hESC/ iPSC to differentiate into mature pancreatic $\beta$ cells in vitro.

In recent years, tremendous success has been achieved in establishing differentiation protocols that can generate glucose-responsive insulin-secreting $\beta$ cells from hESC/ iPSC in vitro expressing mature $\beta$ cell markers, and ameliorating hyperglycemia in diabetic mice following transplantation of these cells [2, 22, 23, 29] (Fig. 1c) (Table 1). In these studies, hESCs/iPSCs were cultured either in low adhesion plate or in three-dimensional (3D) suspension culture with controlled stirring, which promote cell-cell and cell-matrix interactions resulting in the formation of cell aggregates. Sequential and time-dependent use of signaling molecules in such culture systems concurrently guides $\mathrm{hESC} / \mathrm{iPSC}$-derived cells to appropriately differentiate towards pancreatic $\beta$ cells with better phenotypes in vitro. After transplantation into recipient mice, cells residing in the aggregates underwent further differentiation and maturation into mature $\beta$ cells. These simplified differentiation conditions enable the efficient generation of human pancreatic and more restricted endocrine progenitor populations from pluripotent stem cells without unwanted formation of polyhormonal cells. Furthermore, the induced $\beta$ cells in this protocol show both in vitro and in vivo gene expression patterns, ultrastructural characteristics, and glucose responsiveness to insulin secretion that closely resemble those of $\beta$ cells from pancreatic islets [2, 22, 23]. Moreover, compared to previously reported implantations of $\mathrm{hESC} / \mathrm{iPSC}$-derived pancreatic progenitors, for which it took 3-4 months after implantation for cells to mature, recent advances in the generation of $\beta$ cells in vitro substantially shorten the waiting time to therapeutic effects after implantation. In a study, Rezania et al. [22] optimized their previous differentiation protocol by adding factors such as vitamin $C$, protein kinase $C$ activators, transforming growth factor- $\beta$ receptor inhibitors, and thyroid hormones to generate insulin-producing cells at an induction rate of approximately $50 \%$. Furthermore, they identified R428, a selective small-molecule inhibitor of tyrosine kinase receptor AXL, as a crucial factor for the maturation of $\beta$ cells in vitro. Pagliuca et al. [23] also optimized a differentiation method to generate $\beta$ cells from $\mathrm{hESC} / \mathrm{iPSC}$ in vitro at an 
induction efficiency of $>30 \%$. In this study, a scalable suspension-based culture system that adopted from Schulz et al. [19] was used to generate more than $10^{8}$ hPSCs for further differentiation. This protocol takes $4-5$ weeks and involves a unique combination of sequential culture steps using factors that affect signaling in numerous pathways, including signaling by Wnt, activin, hedgehog, EGF, TGF $\beta$, thyroid hormone, and retinoic acid, as well as $\gamma$-secretase inhibition. Later, in 2015, Russ et al. [2] showed that the use of BMP inhibitors to specify pancreatic cells promotes the precocious induction of endocrine differentiation in PDX1+ pancreatic progenitors, which ultimately results in the formation of non-functional polyhormonal cells. Therefore, in their culture system, the commonly used BMP inhibitors were omitted during pancreatic specification, which prevent precocious endocrine formation, while treatment with retinoic acid followed by combined EGF/keratinocyte growth factor (KGF) efficiently generates both PDX1+ and subsequent PDX1+/NKX6.1+ pancreatic progenitor populations, respectively. The precise temporal activation of endocrine differentiation in PDX1+/NKX6.1+ progenitors finally produces glucose-responsive $\beta$-like cells in vitro at an induction efficiency of $\sim 60 \%$. Thus, this protocol is considered to be more closely resembles key aspects of early human pancreas development and, as such, represents an improvement over previous protocols. All these observations suggest that insulin-producing cells suitable for diabetes cell therapies can be produced from hESC/iPSC in vitro. However, the formation of $\mathrm{hESC} / \mathrm{iPSC}$-induced $\beta$ cells in vitro depends on multiple factors, such as the use of platforms/ materials, application of suspension culture, use of a large number of growth factors and their combinations, and the timing of rotating the cultures. In these multistage protocols, although the final cell population has only about 30 $60 \% \beta$-like cells, the majority of the remaining cell population comprised relatively uncharacterized cells that may be undifferentiated progenitors or other types of unwanted cells. Thus, improving differentiation efficiency to generate higher percentages of $\beta$ cells in vitro remains an important challenge.

A similar iPSC-derived $\beta$ cell generation protocol has been reported for patients with type 1 diabetes (T1D) [27, 28]. Millman et al. [27] reported that the induced cells express $\beta$ cell markers, respond to glucose both in vitro and in vivo, prevent alloxan-induced diabetes in mice, and respond to several categories of antidiabetic drugs. No major differences were observed in T1D stem cell-derived $\beta$ cells compared to stem cell-induced $\beta$ cells derived from non-diabetic patients. Furthermore, T1D iPSC-derived $\beta$ cells responded to different forms of $\beta$ cell stress in an in vitro disease model. Manzar et al. [28] generated glucose-responsive insulin-producing cells via 3D culture. In this study, T1D iPSCs were initially resistant to differentiation, but transient demethylation treatment significantly enhanced the yield of insulin-producing cells. The cells responded to high-glucose stimulation by secreting insulin in vitro. The shape, size, and number of their granules were identical to those found in cadaveric $\beta$ cells. When these insulin-producing cells were transplanted into immunodeficient mice that had developed streptozotocin (STZ)-induced diabetes, hyperglycemia decreased dramatically, so that the mice become normoglycemic. Thus, T1D iPSC-derived $\beta$ cells are a suitable candidate for use as an autologous cell source for the treatment of diabetes. However, a more efficient culture system is required to generate functional and terminally differentiated $\beta$ cells for future research and clinical applications.

\section{Islet organoid generation for diabetes treatment}

Pancreatic islets are composed of ECs, including insulin-producing $\beta$ cells, glucagon-producing $\alpha$ cells, somatostatin-producing $\delta$ cells, pancreatic peptide-producing (PP) cells, and ghrelin-producing $\varepsilon$ cells [75-77]. After functional maturation, these ECs in the islets help to regulate blood glucose levels. Reciprocal interactions among ECs in the islets are critical for regulation of insulin secretion in response to glucose [78-80]. Thus, pancreatic islet structures offer an effective means of physiologically regulating insulin secretion in patients with diabetes mellitus.

Organoids are a group of primary cells, ESCs, or iPSCs grown in vitro that owe their self-renewal capacities and ability to differentiate into 3D structures that assume a similar organization and functionality as an organ. The generation of islet organoids containing mature $\beta$ cells with full functionality is yet to be demonstrated. However, generating such functional organoids would be valuable in performing pathology studies of diabetes development, treatment, and drug screening [81, 82]. In the last decade, several research groups have reported on the generation of $\mathrm{hESC}$ /iPSC-derived islet-like clusters/aggregates, as well as islet-like organoids [81-87]. In the early studies, only the feasibility of generating islet-like clusters or aggregates from $\mathrm{hESC/iPSC}$ was studied. However, in recent years, considerable success has been achieved in generating islet-like organoids (Fig. 3). Islet-like organoids developed from hPSC by Kim et al. [86] showed glucose responsiveness in vitro, as well as in vivo. In that study, ECs expressing pancreatic endocrine hormones were first generated from hESC and iPSC using a step-wise protocol, and EC clusters (ECCs) were then formed spontaneously in 1 day from the dissociated ECs in an optimized 3D culture. The sizes of the hESC-derived ECCs were approximately 50 $150 \mu \mathrm{m}$ in diameter, which is similar to the sizes of human pancreatic islets. The ECCs comprised several pancreatic EC types, except for $\alpha$ cells, and thus showed 


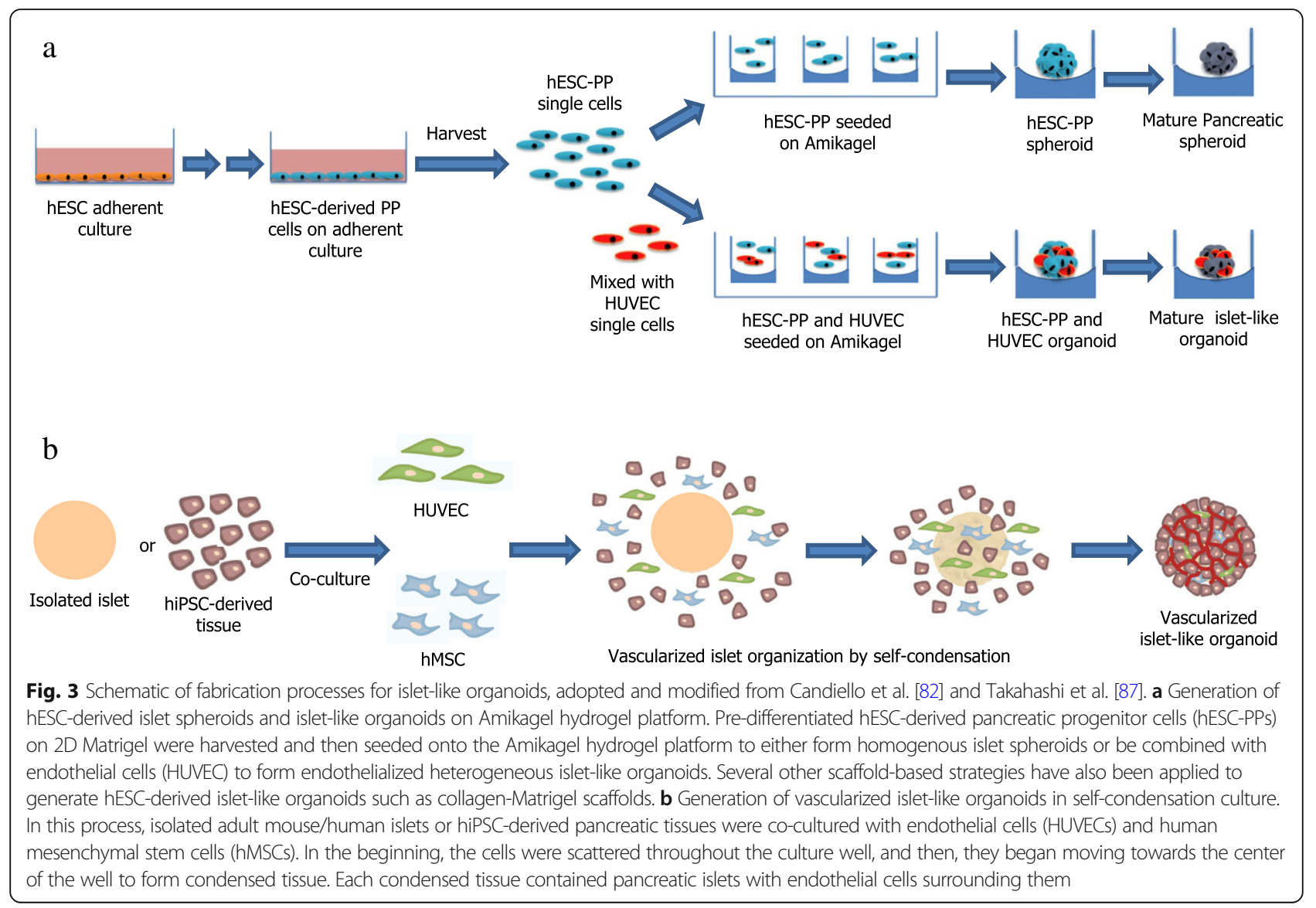

that hESC-derived ECCs are, to some extent, analogous to human pancreatic islets in terms of size and cell composition. Levels of $\beta$ cell-associated gene transcription and GSIS were found to be higher in ECCs than in ECs. In addition, intracellular $\mathrm{Ca}^{2+}$ influx oscillated in ECCs during glucose stimulation, and STZ-treated diabetic mice transplanted with ECCs became normoglycemic within 3 days after transplantation and survived for approximately 2 months. This study, therefore, supported the idea that functional islet-like organoids can be generated from hPSCs, which could serve as an alternative source of therapeutic cells for the treatment of diabetes. Another study by Wang et al. [81] demonstrated the development of islet organoids from hESC in 3D biomimetic scaffolds using several growth factors, which promote pancreatic EC differentiation. The organoids formed in this study consisted of pancreatic $\alpha, \beta, \delta$, and PP cells, and, importantly, most insulin-secreting cells generated did not co-express glucagon, somatostatin, or PP. Mature $\beta$ cell marker genes were expressed, and insulin-secretory granules, which are indications of $\beta$ cell maturity, were detected in these 3D-induced cell clusters. The 3D-induced organoid cells were sensitive to glucose levels; exposing the cells to a high concentration of glucose induced a sharp increase in insulin secretion.
However, these islet organoids were not transplanted into animal models to confirm their biological function. The conventional 2D culture of stem cells over several passages influence cell phenotype and function [88]. Cells are only partially polarized on a flat substrate. In contrast, 3D cell culture on a specialized matrix prevents cells from attaching to the bottom of the plate by maintaining the cells in suspension or embedding them in the matrix in which cell-cell and cell-matrix interactions are maintained, thereby promises phenotypic maintenance and self-assembly of functional tissue-like polarized structures [89-91]. 3D platforms recapitulate mechanical and biochemical stimuli as present in native tissue and thus dictate polarization [92]. However, such structures often do not entirely match multicellular organization seen in native tissue. Extracellular matrix (ECM) is a critical regulator of cellular processes which serve diverse functions such as sequestering signaling molecules and transmitting ligand-specific cues via cell receptors and is amenable to synthesis, degradation, and reassembly over time [93]. Cells readily shape and remodel their extracellular environment by enzymatically degrading and resynthesizing the ECM. In tissues, ECM not only acts as an immobilization platform for a higher order of self-assembly but also facilitates the relay of 
biochemical and mechanical cues in a buffered and hydrated environment [93]. ECM interactions have been shown to improve $\beta$ cell proliferation [94], insulin secretion [95, 96], and islet development [96-98]. Collagen has been used widely for 3D stem cell cultures [99]. A collagen scaffold constitutes a soft and flexible fibrous network that maintains cell morphology and allows cells to freely reach out, migrate, and form 3D structures. However, collagen alone is insufficient to provide multiple cues and sophisticated geometry and composition that exist in a native extracellular matrix. In previous studies, the combination of collagen with Matrigel, a complex heterogeneous mixture of basement membrane proteins such as laminin, collagen IV, fibronectin, heparin sulfate proteoglycans, and entactin, has been used as the underlying material to reconstruct cardiac muscle and uterine tissues in vitro [100, 101]. In a study, Wang et al. [81] used a four-stage differentiation strategy to differentiate hESC into pancreatic endoderm and to mature these cells into islet organoids within collagenMatrigel scaffolds. Their results showed that augmentation of collagen scaffolds with Matrigel creates better 3D niches for islet organoid development from hESC. Although neither Matrigel nor rat tail collagen I is a US Food and Drug Administration-approved material for clinical applications, the study only demonstrated the feasibility of generating islet organoids from hESC. However, the cell clusters can be purified by enzymatically digesting the scaffolds. Another alternative is to use a porcine decellularized ECM to construct scaffolds.

A shortage of donor islets is currently limiting the widespread implementation of islet transplantation to treat diabetes [102]. In response to these needs, recent studies have focused primarily on deriving islet $\beta$ cells from $\mathrm{hESC} / \mathrm{iPSC}$ as an alternative to donor islets $[2,22,23,27-29]$. The non-endocrine components of islets also play a critical role in their function. Previously, heterogeneous pancreatic organoids have been generated by aggregating adult mouse $\beta$ cells with endothelial and mesenchymal cells [103]. These organoids were found to successfully integrate with host vasculature and normalize blood glucose in diabetic mice. Systematic generation of heterogeneous organoids in vitro requires an organ-specific cell source and a 3D culture platform to induce self-organization, lineage specification, functional maturation of organ-specific cells, and integration of supporting cell populations [104, 105]. Scaffold-based strategies have primarily relied on laminin-rich Matrigel, as well as other natural or synthetic biomaterials, which typically confined cells within the 3D scaffold. Recently, islet organoids have been generated from hPSCs by aggregating these cells into homogenous 3D islet-like spheroids using 2D non-adherent culture [86] or by embedding them in a collagen-Matrigel matrix [81]. Effective bioengineered platforms that will support specific organoid production, fine control over the organoid size and cellular composition, scaling up of production, and ease of organoid recovery after culture are still needed. Hydrogels have been a favored choice of materials in tissue engineering applications due to their ability to mimic the architecture and mechanics of pliable cellular microenvironment [106, 107]. Tissue-like fluidity, facile transport of soluble nutrients, ease of fabrication, and integration with biological interfaces are some of the main advantages of a hydrogel system. In a recent study, islet organoids of a precise size and cellular heterogeneity were engineered from hESC-derived pancreatic islet cells utilizing a novel hydrogel platform, Amikagel [82] (Fig. 3). The Amikagel-based platform was shown to facilitate controlled and spontaneous, rather than forced, aggregation of hESC-derived pancreatic progenitor cells (hESC-PPs) into robust homogeneous spheroids. The formation of Amikagel-induced hESC-PP spheroids enhanced pancreatic islet-specific PDX1 and NKX6.1 gene and protein expression, while also increasing the percentage of cells co-expressing both. Amikagel also enabled co-aggregation of hESC-PP with supporting endothelial cells, resulting in self-organized multicellular pancreatic organoids that were closer to islet physiology in terms of their heterogeneity than hPSC-PP homogenous spheroids. These Amikagel-induced hESC-PP spheroids and heterogeneous organoids spontaneously differentiated into mature $\beta$-like cells that show expression of the $\beta$ cell-specific INS1 gene, as well as $\mathrm{C}$-peptide protein, and produce insulin in response to in vitro glucose challenge. After maturation, the Amikagel-induced heterogeneous organoids also show a significantly developed extracellular matrix support system. Therefore, the Amikagel platform could be ideal for engineering multicellular 3D islet organoids from hPSCs. The purpose for inducing and maintaining 3D-aggregated organoids is to enhance tissue- or organ-specific functions by reproducing cells' native environments. Commonly used techniques for engineering islet spheroids neither have precise control over the ultimate size of an aggregate, nor do they support cell inclusion, which is the next step needed to generate islet organoids with multicellular complexity and eventual generation of vascularized constructs. The Amikagel platform is particularly suitable in this context.

A developed extracellular matrix base is important for islet structure, cell health, and overall function, while also being a prerequisite for a developed vascular system [108]. Integration of endothelial cells would be an important initial step towards vascular development [109]. In the context of regenerative medicine, tissue survival and neovessel organization of hESC-derived cells may be dependent on endothelial inclusion and mesenchymal supplementation [110]. In 2018, a complex organoid engineering method to generate pancreatic islets was reported [87] (Fig. 3). Using this protocol, pancreatic islet-like organoids with vascular networks were formed 
by co-culturing either isolated adult mouse/human islet tissues or hiPSC-derived pancreatic tissues with vascular endothelial cells (HUVECs) and human mesenchymal stem cells (hMSCs). Pancreatic islet-like organoids were generated by self-condensation after seeding cells onto the Matrigel bed. Transplantation of these vascularized islet-like organoids into the kidney subcapsule of fulminant type 1 diabetic mice significantly improved the survival of the diabetic mice and effectively normalized blood glucose compared to conventional islet transplantation. This approach, therefore, offers a promising alternative to therapeutic islet transplantation. The functionality of islet organoids generated so far remains partial. Some of the limitations of these organoids are that they often lack cell types needed for complete islet functions and the generation of blood vessels and nerves. To apply islet organoids to the treatment of diabetes, more complete islet structures must be prepared for better function in diabetic recipients. Despite the promise of emerging islet organoid-based approaches, developing vascular networks remains a major challenge to their application in regenerative therapies.

\section{ESC/iPSC-derived $\beta$ cells for diabetes treatment: limitations and challenges}

There are still many points to address and problems to overcome before hESC/iPSC-derived cells can be clinically applied in diabetic patients, including the following: (1) Safety issues: So far, most patient-specific iPSCs have been established with retrovirus vectors. These iPSCs have numerous transgene integrations in their genomes, and these integrations may cause leaky expression that can interrupt the function of endogenous transcription factor networks and lead to differentiation failure. Another important problem of transgene integration is tumorigenic risk after transplantation. In particular, c-Myc, one of the reprogramming factors, is a well-known oncogene, and its reactivation can give rise to transgene-derived tumors in chimeric mice [111]. To make safe iPSCs, one important approach may be eliminating the c-Myc transgene in the reprogramming cocktail. Human and mouse iPSCs can be established from fibroblasts with only Oct $3 / 4$, Sox 2 , and Klf4, but both the efficiency of iPSC generation and the quality of these cells are significantly reduced [112]. Chimeric mice produced with c-Myc-free iPSCs did not show enhanced tumor formation in comparison with control mice. However, retroviral insertions in the genome itself may disturb endogenous gene structure and increase the risk of tumors [113]. To increase the safety of hiPSC-based cell therapies, it is necessary to generate hiPSCs without vector integration and continuous c-MYC expression. The generation of hiPSCs with transient expression from non-integrating vectors $[52,56,114]$ may address these concerns. To date, various integration-free techniques have been reported, including transient expression of reprogramming factors using adenovirus [115] or Sendai virus vectors [116], the piggyBac system [51], episomal vectors $[52,56]$, a minicircle vector $[53]$, and direct delivery of protein [50] or synthetic RNA [54]. However, their iPSC induction efficiencies are lower than those with retrovirus vectors, possibly because of low transduction efficiency and unstable expression [117]. (2) Variation in differentiation efficiencies: Differentiation propensities are reported to vary among hESC lines [118]. Depending on the cell origin or derivation procedure, some iPSC lines also demonstrate varying degrees of differentiation efficiency, resistance to differentiation, or tumorigenicity $[65,84]$. Abnormalities in karyotype and variations in the techniques used to obtain or maintain iPSC lines and epigenetic differences among them have also been considered vital factors that alter differentiation potential. Epigenetic variations are more pronounced in iPSC than ESC. Thus, selection of good iPSC lines with low batch-to-batch variation in differentiation efficiency is essential to differentiating these cells into target lineages prior to use in specific cell therapies [118]. In addition, differentiated cells prepared from patient-specific iPSC can increase the success rate of cell therapies in the future. (3) Formation of polyhormonal cells: Polyhormonal insulin-expressing cells are frequently formed from hESC/iPSC-derived cells in vitro, as discussed above. Available reports suggest that once hESC/iPSC-derived cells become polyhormonal, they cannot be differentiated into mature $\beta$ cells [33]. Therefore, it is necessary to find out the right combination of factors to reduce the formation of polyhormonal cells in culture, as well as to induce these cells into mature $\beta$ cells if they are generated. (4) Xenogeneic contaminations and unknown effects: Although most recent differentiation protocols have been developed on feeder-free culture systems, many protocols still call for a variety of undefined animal-derived products that may have unknown effects on cell characteristics and differentiation ability. The potential consequences of transplanting human cells exposed to animal-derived products into patients could include increased risk of graft rejection, immunoreactions, microbial infectious, prions, and yet unidentified zoonoses [119-121]. To reduce the effects of xenogeneic contamination, Micallef et al. [122] used xeno-free media; however, they used MEF for passaging. In another study, Schulz et al. [19] expanded hESC in xeno-free media without feeder cells, but they used fetal bovine serum during differentiation. Later, Shahjalal et al. [24] expanded and differentiated hESC and iPSC in a synthetic scaffold under completely xeno-free conditions using recombinant and/or humanized components and successfully generated insulin-expressing cells in vitro. 
These studies indicate the feasibility of generating hESC/ iPSC-derived pancreatic $\beta$ cells under xeno-free conditions. For successful clinical applications, hESC/iPSC should be prepared, maintained, and differentiated in xeno-free culture systems. Humanized and/or recombinant factors, chemically defined supplements, and synthetic scaffolds can be applied in vitro to address this issue. (5) Lack of maturation: To date, insulin-expressing cells generated from $\mathrm{hESC} / \mathrm{iPSC}$ in vitro lack the properties of mature pancreatic $\beta$ cells. Transplantation of immature human islet-like cells to immunodeficient mice enables further maturation of islet cells. This is evidenced by human C-peptide secretion in glucose tolerance tests and by morphological and ultrastructural studies [2, 22, 23, 123]. It is important to understand what factors in the in vivo milieu are critical to functional maturation. These could be related to local signals provided by the in vivo niche at the transplant site. Recently, it has been shown that maturation occurs faster and more efficiently in female recipient mice, pointing to the potential role of estrogen receptor signaling in maturation [124]. Gene profiling studies suggest that the creation of mature $\beta$ cells, in which insulin secretion is tightly coupled to glucose concentrations, requires the coordinated upregulation of certain genes and repression of others [125]. A recent report showed that ligand-dependent transcription factor estrogen-related receptor- $\gamma(E R R \gamma)$ is a driver of the oxidative metabolic gene network in mature $\beta$ cells and that its postnatal induction orchestrates the metabolic maturation of $\beta$ cells [123]. This report also indicated that $\beta$ cell-specific $E R R \gamma$-deficient mice are glucose intolerant and fail to appropriately secrete insulin in response to glucose challenge. ERR $\gamma$ expression during postnatal $\beta$ cell maturation drives a transcriptional program that promotes the mitochondrial oxidative metabolism necessary for GSIS. As such, promoting ERR $\gamma$ expression and activity during the late stage of hiPSC differentiation in vitro results in glucose-responsive $\beta$ cells that are capable of restoring blood glucose in type 1 diabetic mice. Thus, future studies to improve functional maturation of insulin-expressing cells should focus on signaling pathways that regulate the maturation of pancreatic $\beta$ cells. (6) Low survival rate and immunogenicity: Because of the lack of a suitable transplantation technique, the recovery of well-demarcated grafts after transplantation into ectopic sites in experimental animals and examination of glucose responsiveness of hESC/iPSC-derived pancreatic cells in vivo are still difficult. This could be due to immune rejection in the host animals. At present, two different transplantation strategies are applied: one is direct implantation of $\mathrm{hESC} / \mathrm{iPSC}$-derived pancreatic cells into ectopic sites, and other one is implantation of a device containing induced pancreatic cells (Fig. 4). In the first method, pretreatment to induce angiogenesis at implantation sites is used to promote engraftment and long-term survival of the implanted cells. One recent study showed that a nylon catheter embedded into the subcutaneous tissues of host mice for 1 month before cell implantation generated a vascularized space [126]. The formation of vascular networks at the implantation site and the implantation of pancreatic cells after inflammatory reactions have diminished develope a less intolerant environment for the implanted cells. In the second method, pancreatic cells are encapsulated in a device made of biocompatible material that includes semipermeable membranes. Oxygen and nutrients can pass through the membranes to promote cell survival, differentiation, and maturation, whereas immune molecules and cells cannot. Several studies have shown that, when implanted subcutaneously into host mice, hESC/ iPSC-derived pancreatic cells encapsulated by these semipermeable membrane devices can further differentiate into mature insulin-secreting cells and survive from host immune responses, primarily by $\mathrm{T}$ cells $[20,21,25$, 35]. In addition, because of vasculogenesis around these devices, the differentiated $\beta$ cells can secrete insulin in response to changes in glucose concentrations. A recent study also demonstrated implantation of hESC-derived $\beta$-like cells encapsulated with an alginate derivative. This device mitigates foreign body responses and implants fibrosis, and induces glycemic correction without immunosuppression in immune-competent mice [127]. These device-based implantation methods can reduce or eliminate the need for immunosuppressive agents. Furthermore, these methods may have the advantage of allowing removal of the implanted cells with the device when adverse events such as tumorigenesis or dysfunction occur. However, it is presently unclear whether protection from soluble antibodies directed against differentiated $\beta$ cells will be a significant problem [128]. Although insulin-expressing cell maturation can occur with or without the implanted cell/device combination, the survival rate of the implanted cells in hosts is still relatively low. Thus, a suitable transplantation technique, along with an effective combination of inducers, is required to overcome this transplantation challenge. Despite several limitations, phase $1 / 2$ clinical trials have already started for the treatment of type 1 diabetes patients using a semipermeable membrane capsule device that carries hESC-derived pancreatic progenitors co-expressing PDX1 and NKX6.1 [36]. This trial has attracted attention worldwide, as it represents an important first step for the development of new stem cell therapies for diabetes. To date, no clinical trials with hiPSC-derived pancreatic cells have been carried out. However, the potential advantages of hiPSC over hESC may make such therapies available in the future. (7) Islet 


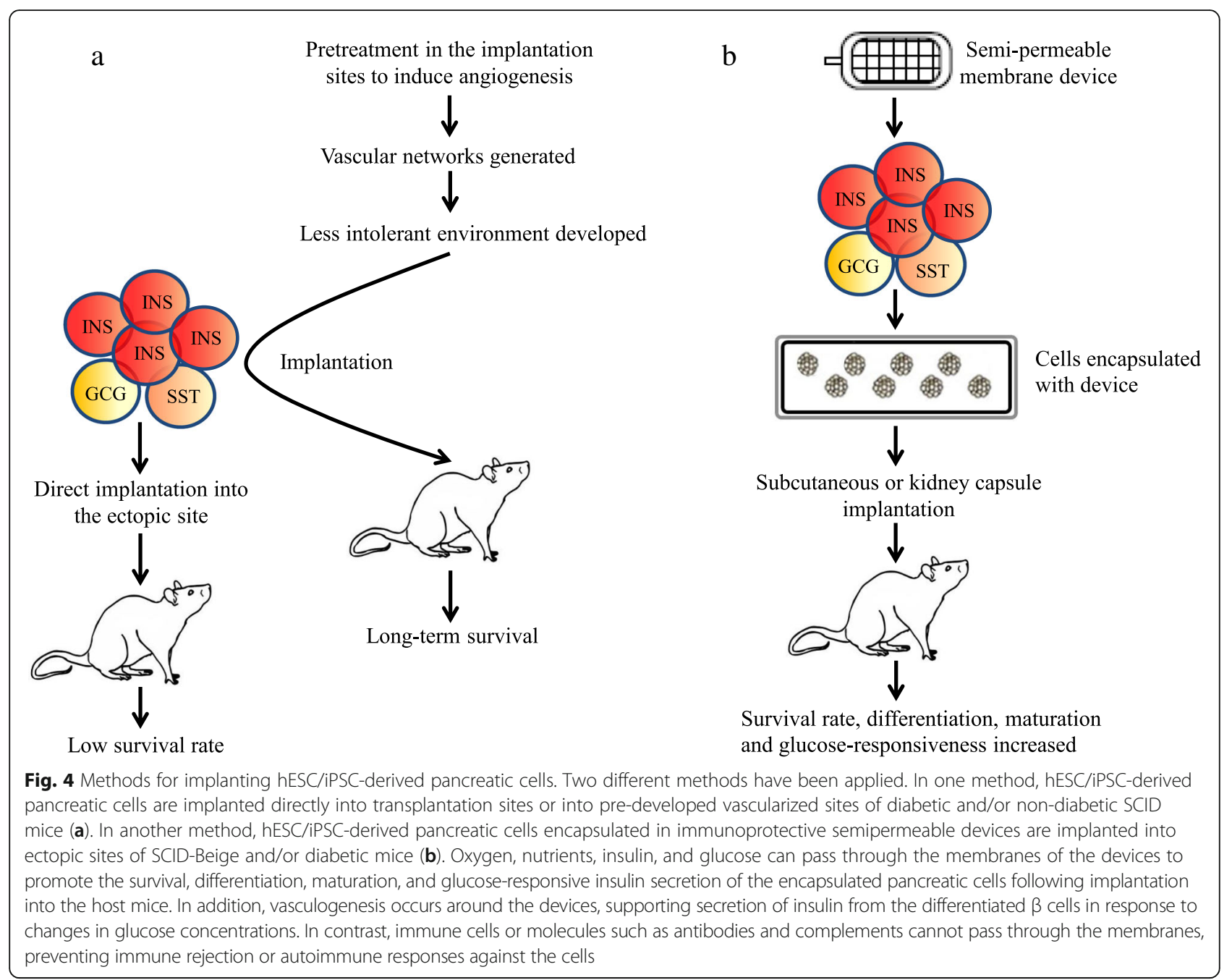

$\beta$ cell heterogeneity: $\beta$ cells in human pancreatic islets have been thought to be a homogenous cell population. Despite this prevailing paradigm, there have also been reports of $\beta$ cell heterogeneity in human islets [129, 130]. Recently, a study by Dorrell et al. has identified four antigenically distinct subtypes of human $\beta$ cells, which are distinguished by differential expression of ST8SIA1 and CD9 [131]. These $\beta$ cell subpopulations are always present in normal adult islets and have diverse gene expression profiles and distinct basal and glucose-stimulated insulin secretion. Dissimilar basal and glucose-stimulated insulin secretion characteristics indicate that the $\beta$ cell subtypes are functionally distinct. Dorrell et al. in their study isolated live pancreatic $\beta$ cells from human islet samples by FACS and co-labeled them with antibodies recognizing ST8SIA1 and CD9 and finally identified four antigenically distinct $\beta$ cell subpopulations. They also accessed the expression of ST8SIA1 and CD9 in sections of human pancreas and further confirmed the existence of four distinct $\beta$ cell subpopulations in human islets. Transcriptome analyses by RNA sequencing of the $\beta$ cell subsets have shown that most of the differentially expressed genes are of unknown function in $\beta$ cells, but some have been clearly associated with insulin secretion or are known to be dysregulated in type 2 diabetes mellitus. Dorrell et al. have also observed that the frequencies of $\beta$ cell subtypes are altered in the majority of individuals with type 2 diabetes. Thus, the $\beta$ cell subpopulations may have relevance to diabetes and this issue needs to be addressed by extensive research. Almost all previous studies have attempted to generate mature $\beta$ cells from human ESCs/ iPSCs. Recently, researchers are mainly focusing on efficient techniques to enhance the yield of mature $\beta$ cells and their successful survival post-transplantation to retain normoglycemia in diabetes. However, $\beta$ cell heterogeneity is an emerging issue. The distinct properties of human $\beta$ cell subtypes found in human islets likely have an important impact on metabolic regulation and human disease processes. Thus, future studies should focus 


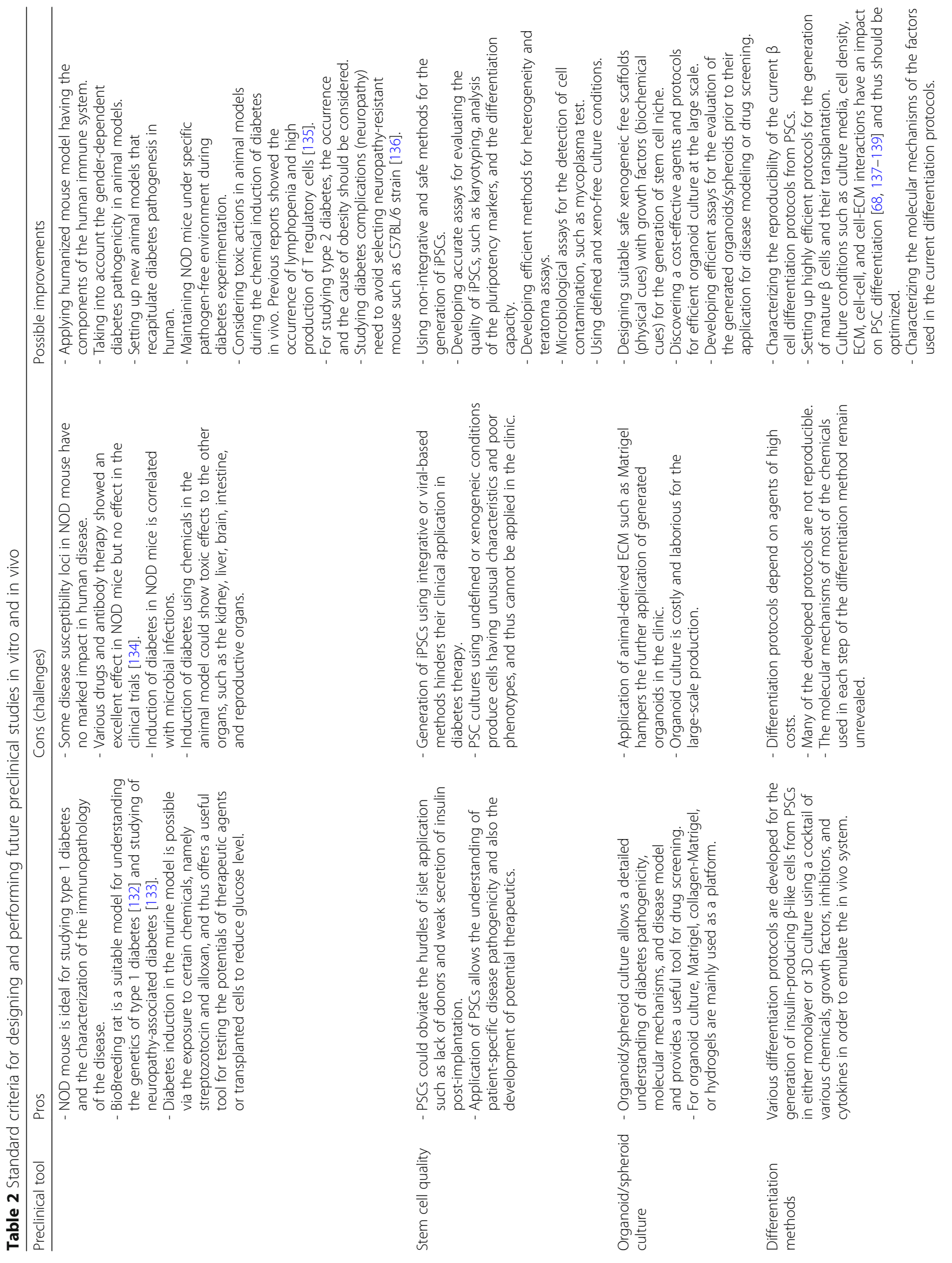




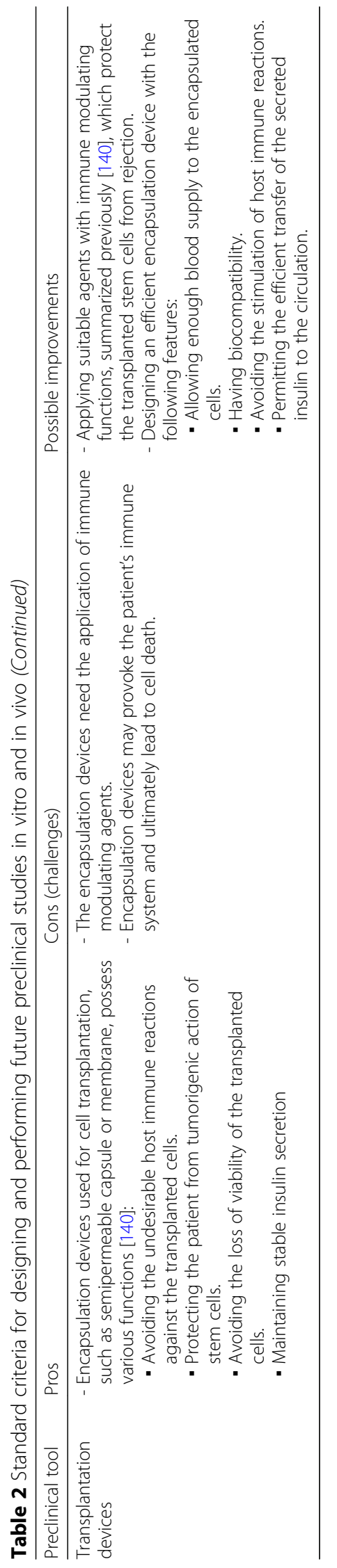


not only on the generation of mature $\beta$ cells but also on the formation of subpopulations of $\beta$ cells from human ESCs/iPSCs and reveal their functional properties to potentially apply in diabetes.

\section{Conclusions}

The ability to obtain a large number of mature insulin-producing cells from $\mathrm{hESC} / \mathrm{iPSC}$ could provide unlimited supplies of surrogate $\beta$ cells to replace damaged cells in patients with diabetes. Insulin-expressing pancreatic cells generated from hESC/iPSC to date appear similar to neonatal cells. Generating mature insulin-expressing cells with the same GSIS capability as endogenous $\beta$ cells and their survival following transplantation into ectopic sites in experimental host animals are challenges for future research. The processes of $\beta$ cell differentiation and islet organoid formation are controlled by a complex network that depends on transcriptional regulation of genes involved in pancreas development, a certain type and number of differentiation factors, and specific types and conditions of stem cell culture. Although many factors are important for the successful generation and transplantation of insulin-secreting $\beta$ cells or islet-like organoids, a suitable combination of factors and conditions stands out as one of the most critical factors. Thus, more work is needed to increase maturity and post-transplant survival of $\mathrm{hESC} / \mathrm{iPSC}$-derived insulin-producing cells or islet-like organoids those resemble endogenous pancreatic $\beta$ cells or islets, respectively. To achieve this goal, chemical screening of various regulatory factors and small molecules in late stages of differentiation in vitro may be a good option. A list of standard criteria for designing and performing future preclinical studies for hPSC-derived $\beta$ cells/islet organoids in vitro and in vivo is given in Table 2. Although a number of considerations currently limit the use of $\mathrm{hESC} / \mathrm{iPSC}$-derived cells in cell replacement therapies, priority should be given to the issues discussed above.

\footnotetext{
Abbreviations

BMP: Bone morphogenetic protein; DE: Definitive endoderm; EC: Hormoneexpressing endocrine cells; ECCs: Endocrine cell clusters; ECM: Extracellular matrix; EGF: Epidermal growth factor; EP: Endocrine progenitor; ERRY: Estrogen-related receptor- $\gamma ;$ ESC: Embryonic stem cells; FGF: Fibroblast growth factors; GCG+: Glucagon-positive cells; GHRL+: Ghrelin-positive cells; GLP-1: Glucagon-like peptide-1; GSIS: Glucose-stimulated insulin secretion; HGF: Hepatocyte growth factor; HUVEC: Human umbilical vein endothelial cell; INS+: Insulin-positive cells; iPSC: Induced pluripotent stem cells; KGF: Keratinocyte growth factor; MEFs: Mouse embryonic fibroblasts; MSCs: Human mesenchymal stem cells; ND: Non-diabetic; NKX6.1: NK6 homeobox 1; NOD: Non-obese diabetes; PDX1: Pancreas/duodenum homeobox 1; PG: Primitive gut tube; PI3K: Phosphatidyl inositol-3-kinase; PP: Pancreatic progenitor; PPY+: Pancreatic polypeptide-positive cells; PSC: Pluripotent stem cell; SCID: Severe combined immunodeficiency; SST +: Somatostatin-positive cells; STZ: Streptozotocin; T1D: Type 1 diabetes; TGF$\beta$ : Transforming growth factor- $\beta$; Wnt: Wnt signaling
}

\section{Funding}

This work was supported by grants from the National Research Foundation (NRF) funded by the Korean government (2017M3A9C6029562 and 2015R1A5A1009701).

\section{Availability of data and materials}

Data sharing is not applicable to this article as no datasets were generated or analyzed during the current study.

\section{Authors' contributions}

HMS contributed to the conception, draft, and modification of the manuscript. AAD contributed to the draft and modification of the manuscript. KMN and TJ contributed to the collection and sorting of the data. SGC contributed to the top-layer design and critical review of the manuscript. All authors read and approved the final manuscript.

Ethics approval and consent to participate

Not applicable.

\section{Consent for publication}

Not applicable.

\section{Competing interests}

The authors declare that there are no competing interests.

\section{Publisher's Note}

Springer Nature remains neutral with regard to jurisdictional claims in published maps and institutional affiliations.

\section{Author details}

${ }^{1}$ Department of Stem Cell \& Regenerative Biotechnology and IDASI (Incurable Disease Animal model \& Stem cell Institute), Konkuk University, 120 Neungdong-ro, Gwangjin-gu, Seoul 05029, South Korea. ²Department of Biochemistry and Molecular Biology, Jahangirnagar University, Savar, Dhaka 1342, Bangladesh.

Published online: 29 December 2018

\section{References}

1. Donath MY, Halban PA. Decreased beta-cell mass in diabetes: significance, mechanisms and therapeutic implications. Diabetologia. 2004;47:581-9.

2. Russ HA, Parent AV, Ringler JJ, et al. Controlled induction of human pancreatic progenitors produces functional beta-like cells in vitro. EMBO J. 2015;34:1759-72.

3. Posselt AM, Szot GL, Frassetto LA, et al. Islet transplantation in type 1 diabetic patients using calcineurin inhibitor-free immunosuppressive protocols based on T-cell adhesion or costimulation blockade. Transplantation. 2010;90:1595-601.

4. Barton FB, Rickels MR, Alejandro R, et al. Improvement in outcomes of clinical islet transplantation: 1999-2010. Diabetes Care. 2012:35:1436-45.

5. Shapiro AM, Ricordi D, Hering BJ, et al. International trial of the Edmonton protocol for islet transplantation. N Engl J Med. 2006;355:1318-30.

6. Shapiro AM. State of the art of clinical islet transplantation and novel protocols of immunosuppression. Curr Diab Rep. 2011;11:345-54.

7. White SA, Shaw JA, Sutherland DE. Pancreas transplantation. Lancet. 2009; 373:1808-17.

8. McCALL MD, Toso C, Baetge EE, et al. Are stem cells a cure for diabetes? Clin Sci. 2010;118:87-97.

9. Dominguez-Bendala J, Inverardi L, Ricordi $C$, et al. Stem cell-derived islet cells for transplantation. Curr Opin Organ Transplant. 2011;16:76-82.

10. D'Amour KA, Bang AG, Eliazer S, et al. Production of pancreatic hormoneexpressing endocrine cells from human embryonic stem cells. Nat Biotechnol. 2006:24:1392-401.

11. Jiang $W$, Shi $Y, Z$ Zhao D, et al. In vitro derivation of functional insulinproducing cells from human embryonic stem cells. Cell Res. 2007;17:333-44

12. Shim JH, Kim SE, Woo DH, et al. Directed differentiation of human embryonic stem cells towards a pancreatic cell fate. Diabetologia. 2007;50: 1228-38.

13. Eshpeter A, Jiang J, Au M, et al. In vivo characterization of transplanted human embryonic stem cell-derived pancreatic endocrine islet cells. Cell Prolif. 2008;41:843-58. 
14. Kroon E, Martinson LA, Kadoya K, et al. Pancreatic endoderm derived from human embryonic stem cells generates glucose-responsive insulin-secreting cells in vivo. Nat Biotechnol. 2008;26:443-52.

15. Chen S, Borowiak M, Fox JL, et al. A small molecule that directs differentiation of human ESCs into the pancreatic lineage. Nat Chem Biol. 2009;5:258-65

16. Zhang D, Jiang W, Liu M, et al. Highly efficient differentiation of human ES cells and iPS cells into mature pancreatic insulin-producing cells. Cell Res. 2009;19:429-38.

17. Kunisada Y, Tsubooka-Yamazoe N, Shoji M, et al. Small molecules induce efficient differentiation into insulin-producing cells from human induced pluripotent stem cells. Stem Cell Res. 2012:8:274-84.

18. Rezania A, Bruin JE, Riedel MJ, et al. Maturation of human embryonic stem cell-derived pancreatic progenitors into functional islets capable of treating pre-existing diabetes in mice. Diabetes. 2012;61:2016-29.

19. Schulz TC, Young HY, Agulnick AD, et al. A scalable system for production of functional pancreatic progenitors from human embryonic stem cells. PLoS One. 2012;7:e37004

20. Bruin JE, Rezania A, Xu J, et al. Maturation and function of human embryonic stem cell-derived pancreatic progenitors in macroencapsulation devices following transplant into mice. Diabetologia. 2013;56:1987-98.

21. Rezania A, Bruin JE, Xu J, et al. Enrichment of human embryonic stem cellderived NKX6.1-expressing pancreatic progenitor cells accelerates the maturation of insulin-secreting cells in vivo. Stem Cells. 2013;31:2432-42.

22. Rezania A, Bruin JE, Arora P, et al. Reversal of diabetes with insulinproducing cells derived in vitro from human pluripotent stem cells. Nat Biotechnol. 2014;32:1121-33.

23. Pagliuca FW, Millman JR, Gurtler M, et al. Generation of functional human pancreatic $\beta$ cells in vitro. Cell. 2014;159:428-39.

24. Shahjalal HM, Shiraki N, Sakano D, et al. Generation of insulin-producing beta-like cells from human iPS cells in a defined and completely xeno-free culture system. J Mol Cell Biol. 2014;6:394-408.

25. Agulnick AD, Ambruzs DM, Moorman MA, et al. Insulin-producing endocrine cells differentiated in vitro from human embryonic stem cells function in macroencapsulation devices in vivo. Stem Cells Transl Med. 2015;4:1214-22.

26. Toyoda T, Mae S-I, Tanaka H, et al. Cell aggregation optimizes the differentiation of human ESCS and iPSCs into pancreatic bud-like progenitor cells. Stem Cell Res. 2015;14:185-97.

27. Millman JR, Xie C, Dervort AV, et al. Generation of stem cell-derived $\beta$-cells from patients with type 1 diabetes. Nat Commun. 2016;7:11463.

28. Manzar GS, Kim EM, Zavazava N, et al. Demethylation of induced pluripotent stem cells from type 1 diabetic patients enhances differentiation into functional pancreatic $\beta$-cells. J Biol Chem. 2017;292:14066-79.

29. Yabe SG, Fukuda S, Takeda F, et al. Efficient generation of functional pancreatic $\beta$-cells from human induced pluripotent stem cells. J Diabetes. 2017:9:168-79.

30. Nostro MC, Sarangi F, Ogawa S, et al. Stage-specific signaling through TGF $\beta$ family members and WNT regulates patterning and pancreatic specification of human pluripotent stem cells. Development. 2011;138:861-71.

31. Xu X, Browning VL, Odorico JS. Activin, BMP and FGF pathways cooperate to promote endoderm and pancreatic lineage cell differentiation from human embryonic stem cells. Mech Dev. 2011;128:412-27.

32. Bruin JE, Erener S, Vela J, et al. Characterization of polyhormonal insulinproducing cells derived in vitro from human embryonic stem cells. Stem Cell Res. 2014;12:194-208.

33. Basford $\mathrm{CL}$, Prentice $\mathrm{K}$, Hardy $\mathrm{AB}$, et al. The functional and molecular characterisation of human embryonic stem cell-derived insulin-positive cells compared with adult pancreatic beta cells. Diabetologia. 2012;55:358-71.

34. Guo $S$, Dai $C$, Guo $M$, et al. Inactivation of specific $\beta$ cell transcription factors in type 2 diabetes. J Clin Invest. 2013;123:3305-16.

35. Kirk K, Hao E, Lahmy R, et al. Human embryonic stem cell derived islet progenitors mature inside an encapsulation device without evidence of increased biomass or cell escape. Stem Cell Res. 2014;12:807-14.

36. ClinicalTrials.gov Identifier: NCT02239354. ViaCyte, Inc., San Diego, CA. http:// viacyte.com/clinical/clinical-trials.

37. Thomson JA, Itskovitz-Eldor J, Shapiro SS, et al. Embryonic stem cell lines derived from human blastocysts. Science. 1998:282:1145-7.

38. Reubinoff BE, Pera MF, Fong CY, et al. Embryonic stem cell lines from human blastocysts: somatic differentiation in vitro. Nat Biotechnol. 2000;18: 399-404.

39. Cowan CA, Klimanskaya I, McMahon J, et al. Derivation of embryonic stemcell lines from human blastocysts. N Engl J Med. 2004;350:1353-6.
40. Takahashi K, Yamanaka S. Induction of pluripotent stem cells from mouse embryonic and adult fibroblast cultures by defined factors. Cell. 2006;126: 663-76

41. Takahashi K, Tanabe K, Ohnuki M, et al. Induction of pluripotent stem cells from adult human fibroblasts by defined factors. Cell. 2007;131:861-72.

42. Yu J, Vodyanik MA, Smuga-Otto K, et al. Induced pluripotent stem cell lines derived from human somatic cells. Science. 2007;318:1917-20.

43. Maherali N, Hochedlinger K. Guidelines and techniques for the generation of induced pluripotent stem cells. Cell Stem Cell. 2008;3:595-605.

44. Federico G, Boué S, Belmonte $\mathrm{JCl}$. Methods for making induced pluripotent stem cells: reprogramming a la carte. Nat Rev Genet. 2011;12:231-42.

45. O'Doherty R, Greiser U, Wang W. Nonviral methods for inducing pluripotency to cells. Biomed Res Int. 2013;2013:705902.

46. Malik N, Rao MS. A review of the methods for human iPSC derivation. Methods Mol Biol. 2013:997:23-33.

47. Zhou YY, Zeng F. Integration-free methods for generating induced pluripotent stem cells. Genomics Proteomics Bioinformatics. 2013;11:284-7.

48. Narayanan $\mathrm{K}$, Mishra S, Singh S, et al. Engineering concepts in stem cell research. Biotechnol J. 2017:12:1700066.

49. Matsui $T$, Leung D, Miyashita $H$, et al. Proviral silencing in embryonic stem cells requires the histone methyltransferase ESET. Nature. 2010;464:927-31.

50. Kim D, Kim CH, Moon II, et al. Generation of human induced pluripotent stem cells by direct delivery of reprogramming proteins. Cell Stem Cell. 2009;4:472-6.

51. Woltjen $K$, Michael IP, Mohseni $P$, et al. piggyBac transposition reprograms fibroblasts to induced pluripotent stem cells. Nature. 2009;458:766-70.

52. Yu J, Hu K, Smuga-Otto K, et al. Human induced pluripotent stem cells free of vector and transgene sequences. Science. 2009;324:797-801.

53. Jia F, Wilson KD, Sun $N$, et al. A nonviral minicircle vector for deriving human iPS cells. Nat Methods. 2010;7:197-9.

54. Warren L, Manos PD, Ahfeldt T, et al. Highly efficient reprogramming to pluripotency and directed differentiation of human cells using synthetic modified mRNA. Cell Stem Cell. 2010;7:618-30.

55. Lee $\mathrm{CH}, \mathrm{Kim} \mathrm{J}-\mathrm{H}$, Lee $\mathrm{HJ}$, et al. The generation of iPS cells using non-viral magnetic nanoparticle based transfection. Biomaterials. 2011;32:6683-91.

56. Okita K, Matsumura $Y$, Sato $Y$, et al. A more efficient method to generate integration-free human iPS cells. Nat Methods. 2011;8:409-12.

57. Choi HY, Lee T-J, Yang G-M, et al. Efficient mRNA delivery with graphene oxide-polyethylenimine for generation of footprint-free human induced pluripotent stem cells. J Control Release. 2016:235:222-35.

58. Chin MH, Mason MJ, Xie W, et al. Induced pluripotent stem cells and embryonic stem cells are distinguished by gene expression signatures. Cell Stem Cell. 2009;5:111-23.

59. Doi A, Park $1 \mathrm{H}$, Wen $\mathrm{B}$, et al. Differential methylation of tissue-and cancerspecific CpG island shores distinguishes human induced pluripotent stem cells, embryonic stem cells and fibroblasts. Nat Genet. 2009;41:1350-3.

60. Mayshar $Y$, Ben-David U, Lavon N, et al. Identification and classification of chromosomal aberrations in human induced pluripotent stem cells. Cell Stem Cell. 2010;7:521-31.

61. Pick M, Stelzer Y, Bar-Nur O, et al. Clone- and gene-specific aberrations of parental imprinting in human induced pluripotent stem cells. Stem Cells. 2009;27:2686-90.

62. Feng Q, Lu SJ, Klimanskaya I, et al. Hemangioblastic derivatives from human induced pluripotent stem cells exhibit limited expansion and early senescence. Stem Cells. 2010;28:704-12.

63. Hu B-Y, Weick JP, Yu J, et al. Neural differentiation of human induced pluripotent stem cells follows developmental principles but with variable potency. Proc Natl Acad Sci. 2010;107:4335-40.

64. Urbach A, Bar-Nur O, Daley GQ, et al. Differential modeling of fragile $X$ syndrome by human embryonic stem cells and induced pluripotent stem cells. Cell Stem Cell. 2010;6:407-11.

65. Miura K, Okada Y, Aoi T, et al. Variation in the safety of induced pluripotent stem cell lines. Nat Biotechnol. 2009;27:743-5.

66. Assady S, Maor G, Amit M, et al. Insulin production by human embryonic stem cells. Diabetes. 2001;50:1691-7.

67. Aguayo-Mazzucato C, Zavacki AM, Marinelarena A, et al. Thyroid hormone promotes postnatal rat pancreatic $\beta$-cell development and glucoseresponsive insulin secretion through MAFA. Diabetes. 2013;62:1569-80.

68. Memon B, Karam M, Al-Khawaga S, et al. Enhanced differentiation of human pluripotent stem cells into pancreatic progenitors co-expressing PDX1 and NKX6.1. Stem Cell Res Ther. 2018;9:15 
69. Nostro MC, Sarangi F, Yang C, et al. Efficient generation of NKX6-1+ pancreatic progenitors from multiple human pluripotent stem cell lines. Stem Cell Rep. 2015;4:591-604.

70. de Krijger RR, Aanstoot HJ, Kranenburg G, et al. The midgestational human fetal pancreas contains cells coexpressing islet hormones. Dev Biol. 1992; 153:368-75.

71. Hrvatin S, O'Donnell CW, Deng F, et al. Differentiated human stem cells resemble fetal, not adult, $\beta$ cells. Proc Natl Acad Sci. 2014;111:3038-43.

72. Riedel MJ, Asadi A, Wang R, et al. Immunohistochemical characterisation of cells co-producing insulin and glucagon in the developing human pancreas. Diabetologia. 2012;55:372-81.

73. Kelly OG, Chan MY, Martinson LA, et al. Cell-surface markers for the isolation of pancreatic cell types derived from human embryonic stem cells. Nat Biotechnol. 2011;29:750-6.

74. Xie R, Everett $\mathrm{L}$, Lim H-W, et al. Dynamic chromatin remodeling mediated by polycomb proteins orchestrates pancreatic differentiation of human embryonic stem cells. Cell Stem Cell. 2013;12:224-37.

75. Rojas A, Khoo A, Tejedo JR, et al. Islet cell development. Adv Exp Med Biol. 2010;654:59-75.

76. Seymour PA, Sander M. Historical perspective: beginnings of the $\beta$-cell: current perspectives in $\beta$-cell development. Diabetes. 2011;60:364-76.

77. Arda HE, Benitez CM, Kim SK, et al. Gene regulatory networks governing pancreas development. Dev Cell. 2013;25:5-13.

78. Rorsman P, Braun M. Regulation of insulin secretion in human pancreatic islets. Annu Rev Physiol. 2013;75:155-79.

79. Benninger RKP, Piston DW. Cellular communication and heterogeneity in pancreatic islet insulin secretion dynamics. Trends Endocrinol Metab. 2014 25:399-406.

80. Peiris $\mathrm{H}$, Bonder CS, Coates PT, et al. The $\beta$-cell/EC axis: how do islet cells talk to each other? Diabetes. 2014:63:3-11.

81. Wang W, Jin $\mathrm{S}$, Ye $\mathrm{K}$, et al. Development of islet organoids from $\mathrm{H} 9$ human embryonic stem cells in biomimetic 3D scaffolds. Stem Cells Dev. 2017:26:394-404.

82. Candiello J, Pavan Grandhi TS, Goh SK, et al. 3D heterogeneous islet organoid generation from human embryonic stem cells using a novel engineered hydrogel platform. Biomaterials. 2018;177:27-39.

83. Jiang J, Au M, Lu K, et al. Generation of insulin-producing islet-like clusters from human embryonic stem cells. Stem Cells. 2007;25:1940-53.

84. Tateishi $\mathrm{K}, \mathrm{He} \mathrm{J}$, Taranova O, et al. Generation of insulin-secreting islet-like clusters from human skin fibroblasts. J Biol Chem. 2008;283:31601-7.

85. Shim JH, Kim J, Han J, et al. Pancreatic islet-like three-dimensional aggregates derived from human embryonic stem cells ameliorate hyperglycemia in streptozotocin-induced diabetic mice. Cell Transplant. 2015:24:2155-68.

86. Kim Y, Kim H, Ko UH, et al. Islet-like organoids derived from human pluripotent stem cells efficiently function in the glucose responsiveness in vitro and in vivo. Sci Rep. 2016;6:35145.

87. Takahashi $Y$, Sekine $K$, Kin $T$, et al. Self-condensation culture enables vascularization of tissue fragments for efficient therapeutic transplantation. Cell Rep. 2018;23:1620-9.

88. Hickman GJ, Boocock DJ, Pockley AG, et al. The importance and clinical relevance of surfaces in tissue culture. ACS Biomater Sci Eng. 2016;2:152-64.

89. Walters NJ, Gentleman E. Evolving insights in cell-matrix interactions: elucidating how non-soluble properties of the extracellular niche direct stem cell fate. Acta Biomater. 2015;11:3-16.

90. Baker LA, Tiriac $\mathrm{H}$, Clevers $\mathrm{H}$, et al. Modeling pancreatic cancer with organoids. Trends Cancer. 2016;2:176-90.

91. Yin X, Mead BE, Safaee $H$, et al. Engineering stem cell organoids. Cell Stem Cell. 2016;18:25-38.

92. Gieni RS, Hendzel MJ. Mechanotransduction from the ECM to the genome: are the pieces now in place? J Cell Biochem. 2008;104:1964-87.

93. Thomas D, O'Brien T, Pandit A. Toward customized extracellular niche engineering progress in cell-entrapment technologies. Adv Mater. 2018;30:1703948.

94. Schuppin GT, Bonner-Weir S, Montana E, et al. Replication of adult pancreatic-beta cells cultured on bovine corneal endothelial cell extracellular matrix. In Vitro Cell Dev Biol Anim. 1993;29A:339-44.

95. Bosco D, Meda P, Halban PA, et al. Importance of cell-matrix interactions in rat islet beta-cell secretion in vitro: role of alpha6beta1 integrin. Diabetes. 2000:49:233-43.

96. Weber LM, Hayda KN, Anseth KS, et al. Cell-matrix interactions improve beta-cell survival and insulin secretion in three-dimensional culture. Tissue Eng Part A. 2008;14:1959-68.
97. Ris F, Hammar E, Bosco D, et al. Impact of integrin-matrix matching and inhibition of apoptosis on the survival of purified human beta-cells in vitro. Diabetologia. 2002;45:841-50

98. Hammar E, Parnaud G, Bosco D, et al. Extracellular matrix protects pancreatic $\beta$-cells against apoptosis: role of short- and long-term signaling pathways. Diabetes. 2004:53:2034-41.

99. Lee $\mathrm{JH}, \mathrm{Yu}$ HS, Lee GS, et al. Collagen gel three-dimensional matrices combined with adhesive proteins stimulate neuronal differentiation of mesenchymal stem cells. J R Soc Interface. 2011;8:998-1010.

100. Zimmermann $W H$, Schneiderbanger $K$, Schubert $P$, et al. Tissue engineering of a differentiated cardiac muscle construct. Circ Res. 2002:90:223-30.

101. Lu S-H, Wang H-B, Liu H, et al. Reconstruction of engineered uterine tissues containing smooth muscle layer in collagen/Matrigel scaffold in vitro. Tissue Eng Part A. 2009;15:1611-8.

102. Li W, Zhao R, Liu J, et al. Small islets transplantation superiority to large ones: implications from islet microcirculation and revascularization. J Diabetes Res. 2014;2014:192093.

103. Takebe T, Enomura M, Yoshizawa E, et al. Vascularized and complex organ buds from diverse tissues via mesenchymal cell-driven condensation. Cell Stem Cell. 2015;16:556-65.

104. Lancaster MA, Knoblich JA. Organogenesis in a dish: modeling development and disease using organoid technologies. Science. 2014;345: 1247125.

105. Takahashi $Y$, Takebe $T$, Taniguchi $H$, et al. Engineering pancreatic tissues from stem cells towards therapy. Regen Ther. 2016:3:15-23.

106. Yanagawa F, Kaji H, Jang Y-H, et al. Directed assembly of cell-laden microgels for building porous three-dimensional tissue constructs. J Biomed Mater Res A. 2011:97:93-102.

107. Kharkar PM, Kiick KL, Kloxin AM. Designing degradable hydrogels for orthogonal control of cell microenvironments. Chem Soc Rev. 2013;42: 7335-72.

108. Stendahl JC, Kaufman DB, Stupp SI. Extracellular matrix in pancreatic islets: relevance to scaffold design and transplantation. Cell Transplant. 2009;18:1-12.

109. Dudley AC. Tumor endothelial cells. Cold Spring Harb Perspect Med. 2012;2: a006536.

110. Kreutziger $\mathrm{KL}$, Muskheli $\mathrm{V}$, Johnson $\mathrm{P}$, et al. Developing vasculature and stroma in engineered human myocardium. Tissue Eng Part A. 2011;17: 1219-28.

111. Okita K, Ichisaka T, Yamanaka S. Generation of germline-competent induced pluripotent stem cells. Nature. 2007:448:313-7.

112. Nakagawa M, Koyanagi M, Tanabe K, et al. Generation of induced pluripotent stem cells without Myc from mouse and human fibroblasts. Nat Biotechnol. 2008:26:101-6.

113. Hacein-Bey-Abina S, Von Kalle C, Schmidt M, et al. LMO2-associated clonal T cell proliferation in two patients after gene therapy for SCID-X1. Science. 2003;302:415-9

114. Stadtfeld M, Nagaya M, Utikal J, et al. Induced pluripotent stem cells generated without viral integration. Science. 2008;322:945-9.

115. Zhou W, Freed CR. Adenoviral gene delivery can reprogram human fibroblasts to induced pluripotent stem cells. Stem Cells. 2009;27:2667-74.

116. Fusaki $\mathrm{N}$, Ban $\mathrm{H}$, Nishiyama A, et al. Efficient induction of transgene-free human pluripotent stem cells using a vector based on Sendai virus, an RNA virus that does not integrate into the host genome. Proc Japan Acad Ser B. 2009;85:348-62

117. Okita K, Yamanaka S. Induction of pluripotency by defined factors. Exp Cell Res. 2010;316:2565-70

118. Osafune K, Caron L, Borowiak M, et al. Marked differences in differentiation propensity among human embryonic stem cell lines. Nat Biotechnol. 2008; 26:313-5.

119. Cobo F, Stacey G, Hunt C, et al. Microbiological control in stem cell banks: approaches to standardisation. Appl Microbiol Biotechnol. 2005;68:456-66.

120. Martin MJ, Muotri A, Gage F, et al. Human embryonic stem cells express an immunogenic nonhuman sialic acid. Nat Med. 2005;11:228-32.

121. Skottman $H_{1}$ Hovatta $O$. Culture conditions for human embryonic stem cells. Reproduction. 2006;132:691-8.

122. Micallef SJ, Li X, Schiesser JV, et al. INS ${ }^{G F P / W}$ human embryonic stem cells facilitate isolation of in vitro derived insulin-producing cells. Diabetologia. 2012:55:694-706.

123. Yoshihara $E$, Wei Z, Lin CS, et al. ERRy is required for the metabolic maturation of therapeutically functional glucose-responsive $\beta$ cells. Cell Metab. 2016;23:622-34 
124. Saber N, Bruin JE, O'Dwyer $\mathrm{S}$, et al. Sex differences in maturation of human embryonic stem cell-derived $\beta$ cells in mice. Endocrinology. 2018;159:1827-41.

125. Schuit F, Van Lommel L, Granvik M, et al. ß-cell-specific gene repression: a mechanism to protect against inappropriate or maladjusted insulin secretion? Diabetes. 2012;61:969-75.

126. Pepper AR, Gala-Lopez B, Pawlick R, et al. A prevascularized subcutaneous device-less site for islet and cellular transplantation. Nat Biotechnol. 2015;33: 518-23.

127. Vegas AJ, Veiseh $\mathrm{O}$, Gurtler $\mathrm{M}$, et al. Long-term glycemic control using polymer encapsulated human stem-cell derived $\beta$-cells in immune competent mice. Nat Med. 2016;22:306-11.

128. Weir GC. Islet encapsulation: advances and obstacles. Diabetologia. 2013;56: 1458-61.

129. Hermann M, Pirkebner D, Draxl A, et al. Dickkopf-3 is expressed in a subset of adult human pancreatic beta cells. Histochem Cell Biol. 2007;127:513-21.

130. Saisho $Y$, Harris PE, Butler $A E$, et al. Relationship between pancreatic vesicular monoamine transporter 2 (VMAT2) and insulin expression in human pancreas. J Mol Histol. 2008;39:543-51.

131. Dorrell C, Schug J, Canaday PS, et al. Human islets contain four distinct subtypes of $\beta$ cells. Nat Commun. 2016;7:11756.

132. Wallis $\mathrm{RH}$, Wang $\mathrm{K}$, Marandi $\mathrm{L}$, et al. Type 1 diabetes in the $\mathrm{BB}$ rat: $\mathrm{a}$ polygenic disease. Diabetes. 2009;58:1007-17.

133. Zhang W, Kamiya H, Ekberg K, et al. C-peptide improves neuropathy in type 1 diabetic BB/Wor-rats. Diabetes Metab Res Rev. 2007;23:63-70.

134. von Herrath M, Filippi C, Coppieters K. How viral infections enhance or prevent type 1 diabetes-from mouse to man. J Med Virol. 2011;83:1672.

135. Muller YD, Golshayan D, Ehirchiou D, et al. Immunosuppressive effects of streptozotocin-induced diabetes result in absolute lymphopenia and a relative increase of T-regulatory cells. Diabetes. 2011;60:2331-40.

136. Brosius FC, Alpers CE, Bottinger EP, et al. Mouse models of diabetic nephropathy. J Am Soc Nephrol. 2009;20:2503-12.

137. Gage BK, Webber TD, Kieffer TJ. Initial cell seeding density influences pancreatic endocrine development during in vitro differentiation of human embryonic stem cells. PLoS One. 2013:8:e82076.

138. Raza A, Chang SK, Lin CC. The influence of matrix properties on growth and morphogenesis of human pancreatic ductal epithelial cells in 3D. Biomaterials. 2013;34:5117-27.

139. Shih HP, Panlasigui D, Cirulli V, et al. ECM signaling regulates collective cellular dynamics to control pancreas branching morphogenesis. Cell Rep. 2016;14:169-79.

140. Sneddon JB, Tang Q, Stock $P$, et al. Stem cell therapies for treating diabetes: progress and remaining challenges. Cell Stem Cell. 2018;22: $810-23$ 